\title{
Examination of Beluga-Habitat Relationships through the Use of Telemetry and a Geographic Information System
}

\author{
DAVID G. BARBER, ${ }^{1,2}$ ERIC SACZUK ${ }^{1}$ and PIERRE R. RICHARD ${ }^{3}$
}

(Received 19 November 1999; accepted in revised form 27 September 2000)

\begin{abstract}
The spatial and temporal relationships between belugas (Delphinapterus leucas) and two characteristics of their habitat-bathymetry and ice concentration-were examined. Observed location-habitat correspondence histograms were compared to random location-habitat histograms, using a Kolmogorov-Smirnoff (K-S) statistical test. Results show that beluga distribution is bimodal with respect to bathymetry, with a larger mode in shallow water and a smaller mode in water approximately $500 \mathrm{~m}$ deep. They occur more often than expected by chance in the $0 / 10$ ice class and less often than expected in the 10/10 ice class. Males and females associate differently with both depth and ice concentration. Females associate with bathymetry very differently in the fall than in the summer. There is a general tendency for males in the eastern North American Arctic to be associated with shallow water during the summer and deeper water (modes at 100 and $500 \mathrm{~m}$ ) in the fall. Female locations are associated more often with the $0 / 10$ ice class and less often with the 10/10 class than expected by chance. These trends were stronger in the western than in the eastern portions of the Canadian Arctic.
\end{abstract}

Key words: bathymetry, beluga, climate change, Delphinapterus leucas, Geographic Information System, habitat, sea ice

RÉSUMÉ. On a étudié les rapports spatiaux et temporels entre les bélougas (Delphinapterus leucas) et deux caractéristiques de leur habitat (bathymétrie et concentration de glace). À l'aide d'un test statistique de Kolmogorov-Smirnov (K-S), on a comparé les histogrammes de la correspondance observée emplacement-habitat à des histogrammes emplacement-habitat pris au hasard. Les résultats montrent que la distribution du bélouga est bimodale en ce qui a trait à la bathymétrie, un mode plus grand étant associé à l'eau peu profonde et un mode plus petit à l'eau profonde d'environ $500 \mathrm{~m}$. On les trouve plus fréquemment qu'on ne peut le prédire au hasard dans de la glace de cote 0/10 et moins souvent dans de la glace de cote 10/10. Les mâles et les femelles s'associent différemment selon la profondeur comme la concentration de glace. Les femelles s' associent très différemment avec la bathymétrie en automne et en été. Dans les mers arctiques de l'Amérique du Nord orientale, il y a une tendance générale pour les mâles à s'associer aux eaux peu profondes durant l'été et aux eaux plus profondes (modes à 100 et $500 \mathrm{~m}$ ) en automne. Les emplacements des femelles sont associés plus souvent à la glace de cote 0/10 et moins souvent à la cote 10/10 qu'on ne peut le prédire au hasard. Ces tendances étaient plus marquées dans les parties occidentales que dans les zones orientales de l'Arctique canadien.

Mots clés: bathymétrie, bélouga, changement climatique, Delphinapterus leucas, système d'information géographique, habitat, glace marine

Traduit pour la revue Arctic par Nésida Loyer.

\section{INTRODUCTION}

The polar regions of the planet will likely experience an increase in temperature in response to a $\mathrm{CO}_{2}$ enhanced atmosphere (IPCC, 1996). It is thought that this increase will be due to a variety of feedback mechanisms operating across the ocean-sea ice-atmosphere interface. Of several mechanisms identified, the "sea ice-albedo" feedback mechanism appears to be a significant component of the system. This mechanism illustrates that as the extent of sea ice is reduced (particularly in spring and fall), more energy is transferred from the atmosphere to the ocean. This positive feedback raises the regional atmospheric temperature, thereby producing a further reduction in ice concentration (percent cover per unit area).

Recent evidence suggests that this response has in fact already begun. Between 1978 and 1998, there was an annual average reduction of about $34600 \mathrm{~km}^{2}$ in the extent of sea ice over the entire Northern Hemisphere (Parkinson et al., 1999). This reduction is spatially heterogeneous, with larger decreases in particular locations (e.g., the Chukchi and Laptev Seas) and slight increases in extent in other regions (e.g., Baffin Bay). Independent evidence confirms a reduction in both the areal extent of the sea ice

\footnotetext{
${ }^{1}$ Centre for Earth Observation Science, Department of Geography, The University of Manitoba, Winnipeg, Manitoba R3T 2N2, Canada

${ }^{2}$ Corresponding author: dbarber@umanitoba.ms.ca

${ }^{3}$ Department of Fisheries and Oceans, Arctic Research Division, Freshwater Institute Science Lab, 501 University Crescent, Winnipeg, Manitoba R3T 2N6, Canada

(C) The Arctic Institute of North America
} 
(Johannessen et al., 1999) and its thickness (Rothrock et al., 1999). Strategies by which belugas (Delphinapterus leucas) respond and adapt to climate change will depend on how and why they select particular habitats.

Relationships between belugas and their habitat have traditionally been investigated using visual observations from boats and aircraft (e.g., Moore and DeMaster, 1998) and by marking and occasionally recapturing individual whales. Each of these approaches is restricted spatially and temporally. Both approaches can provide useful information for population indexing, but they cannot provide an overview of the animal's behaviour in different types of habitat. Satellite-linked tracking and dive recording have allowed researchers to increase their understanding of beluga movements and behaviour (Martin and Smith, 1990; Richard et al., 1998; Heide-Jørgensen et al., 1998). Satellite telemetry provides locations of individuals several times daily and makes it possible to track their movements and quantify their use of specific marine or estuarine habitats. Geographic Information Systems (GIS) can then use these telemetry locations to characterize the spatial and temporal relationships between belugas and the habitats they occupy.

In this paper, we examine the relationships between beluga occurrence and two environmental parameters: water depth and sea ice concentration. As a preface to this analysis, we examine the assumption of a continuous distribution of whale locations in time, as required by our statistical analysis ("assumption testing"). We then address our primary objective by examining three interrelated research questions:

1) Habitat Selection: Which bathymetric and sea ice habitats do beluga whales select?

2) Gender- and Region-Based Habitat Selection: Does the relationship in (1) vary by gender and region?

3) Gender- and Season-Based Habitat Selection: Does the relationship in (1) vary by gender and season?

To date, most beluga studies have taken place in estuarine or coastal summer habitats. The results of broad-scale aerial surveys and shore-based watches have been interpreted as indicating that belugas prefer loose to heavy pack ice (Finley et al., 1982; McLaren and Davis, 1982). Heavy ice has been hypothesized to function as a barrier to beluga movement across the central North American Arctic (Sergeant and Brodie, 1975). We reconsider this hypothesis in the present study.

\section{METHODS}

Telemetry and habitat data were available from a large geographic region in the North American Arctic. We separated these data into eastern and western subsets (Fig. 1). Whales were tagged in multiple years from three locations: the Mackenzie Estuary, the south coast of Devon
Island, and the north and east coasts of Somerset Island (Richard et al., 2001a, b). In the west, tags were attached to 30 whales and operated within the periods 10 July -3 October 1993, 4 July-21 October 1995, and 27 July-2 October 1997. In the east, tags were attached to 26 animals and operated within the periods 12 September -4 November 1995, 3 September- 18 November 1996, and 14 July27 November 1996. From these tagged animals, we obtained a total of 26046 whale locations. We excluded low-accuracy locations, reducing the data to a subset of 19969 locations. This subset had the advantage of decreasing the within-sample variability in positional accuracy.

\section{Telemetry}

The belugas were live-captured and equipped with satellite-linked position transmitters ("tags"). Tags consisted of a housing, sensors to record data, an antenna, lithium batteries, circuitry to produce the signal itself, and a microprocessor. The microprocessor was programmed to control the sensors, collect and compress data, and trigger the transmitter at each surfacing. The tag started transmitting data to the Argos satellite whenever the animal surfaced and exposed the antenna. Transmissions were repeated every 40 seconds. The transmitter's latitude and longitude were calculated from the difference in signal frequency between repeated signals while the satellite was passing overhead. Further details of the live-capture, tag attachment, operation, and data processing are given in Richard et al. (2001a, b).

\section{The GIS Database}

The GIS database was created using three sources of spatial information: telemetry data, Digital Bathymetric Models (DBMs), and weekly composite sea ice charts. The telemetry data were gathered using the methods described above and were reduced to Microsoft Excel-compatible spreadsheets. The spreadsheets were organized according to either date or whale tag number. The DBMs were developed using TBase or TerrainBase Global 5-minute Terrain Model and a bathymetric database provided by the Geological Survey of Canada (GSC) and the Canadian Hydrographic Service (CHS) (MacNab and Monahan, 1997). The latter data set was determined to be more accurate than the TBase data set despite the lack of depths in a few areas. Thus the two bathymetric data sets were combined into a comprehensive DBM of the Arctic Ocean. Because of the large volume of data, two separate models were created, one for the eastern Arctic (east) and one for the western Arctic (west) (Fig. 1). Weekly composite ice charts were acquired from the Canadian Ice Service (CIS) in both paper and digital form. Specific methods pertaining to these sources of data are as follows:

The GEBCO digital bathymetric software was used to produce $100 \mathrm{~m}$ contour interval bathymetric data for the study area. Shorelines generated were based on the World 


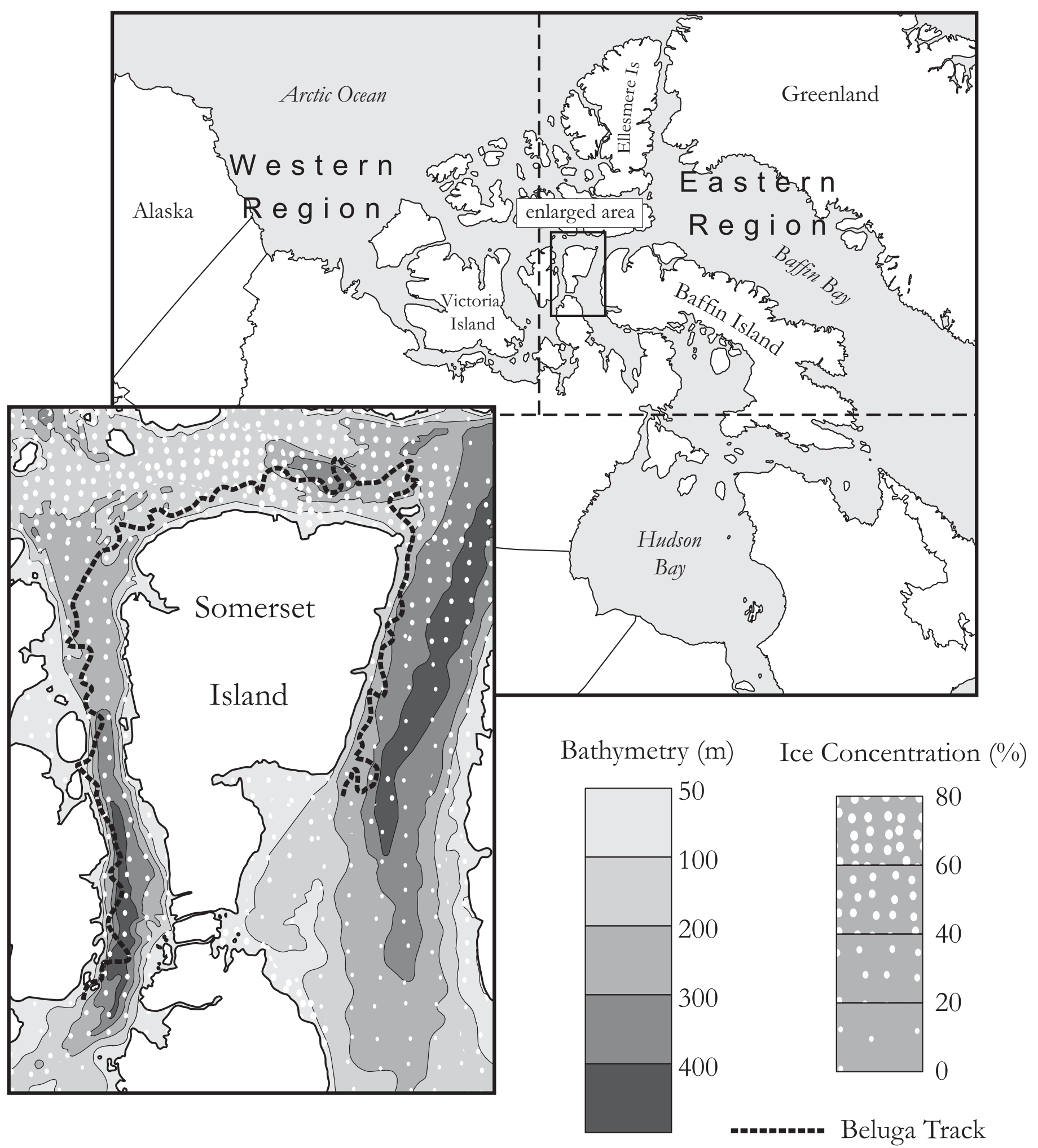

Beluga ID 17008 for the week of September 24 - 30, 1996.

FIG. 1. Map of the study area, showing division into eastern and western Arctic regions. The inset shows the bathymetry and ice concentration of the waters surrounding Somerset Island. The dotted line tracks the route of beluga no. 17008 for the week of 24-30 September 1996.

Vector Shoreline 1:12 000000 data set. Each of these data sets was projected into a Lambert conic-conformal reference system and rasterized. The GSC/CHS database was also projected into the Lambert conic-conformal 
reference system and overlaid onto the bathymetric map to fill gaps in the GEBCO dataset. As a final step, the bathymetric model was "smoothed" using a median $3 \times 3$ filter to reduce the presence of "spikes" or "artifacts" that were sometimes generated by the interpolation procedure.

Environment Canada ice charts were acquired in both analogue (paper) and digital form. These data were reviewed for completeness, and the paper maps were digitized and integrated with the existing digital products. On-screen digitizing was used to segment the raster scans into unique polygons of ice type and concentration. The "egg-codes" present on the ice charts were used to determine the type and concentration of each ice polygon. Examples of the bathymetry and sea ice concentration images are provided (Fig. 1).

Our research questions required that we extract information on depth and ice concentration for each whale as a function of location and season. We facilitated this by producing a geometrically corrected database of "overlays" of the variables of interest. Polynomial models were computed to project the data into a common geographic reference to a precision of better than 1 raster pixel $(5 \mathrm{~km})$. The number of whale locations on each map was determined by the time frame of the ice charts (weekly). Each ice chart contained a composite of ice concentration for a seven-day period. Data extraction was carried out by digitally overlaying the individual whale location maps onto the respective ice charts and DBM. Coincident ice and depth variables were then extracted for each of the 19969 whale locations.

\section{Spatial Analysis}

In the present context, the term "location" means the telemetry position and its associated spatial and temporal co-ordinate. The habitat variables are bathymetry, expressed as depth classes, and sea ice concentration, expressed as areal coverage in tenths. To create a testable hypothesis, we needed to generate correspondence histograms (i.e., whale location spatially coincident with a particular habitat variable). Our test metric required the generation of a random correspondence histogram. The premise here is that by generating a number of random locations, we can examine the expected habitat relationships under a "randomness" assumption. These random locations were selected by enumerating the total number of available locations (all areas of ocean but not land) and randomly selecting an appropriate number from this set for each analysis. Our logical and statistical assumptions required that three conditions be met. First, the random set of locations generated had to be of size $\mathrm{N}$, where $\mathrm{N}$ equals the number of "real" whale locations derived from the telemetry data set. Second, the habitat "space" had to be exactly the same in both the real and random location cases. This meant that land had to be excluded from the sample space when selecting the random locations, and we needed to use the same spatial variables for ice and depth.
Finally, we also had to generate cumulative frequency histograms of "real" locations with particular habitat variables and the associated random correspondence histograms, using the same habitat variables.

The resulting cumulative frequency histograms can be considered continuous variables, since the location and habitat values could range throughout the magnitude of the respective variables. The statistical hypothesis to be tested was whether a histogram generated from the real locations was statistically distinguishable from that which would arise given a random distribution of whales within exactly the same available habitat. The Kolmogorov-Smirnoff (K-S) statistic is a suitable metric for contrasting two such cumulative frequency distributions (Sokal and Rohlf, 1981). The premise of this analysis is that if there is a statistical difference between the observed and the random locations (for the same habitat), then we can examine the real location histogram for insight regarding the habitat preferences of the telemetered whales.

Two types of bias can affect our analysis: system bias and behavioural bias. System bias is created by the physical operations of the telemetry system (tags and satellites). Behavioural bias is created when there is an unequal probability of producing a telemetered position because of the behaviour of the animal (e.g., spending more time diving; remaining in areas of heavy ice, etc.). As a prerequisite to the frequency analysis (described above), we examined these issues of bias from the perspective of meeting the assumptions of our K-S statistic (data continuity in space and time). To address system bias, we examined the pattern of telemetry locations throughout a diurnal cycle for all animals and then for animals separated according to region, season, and gender. If the whale locations were uniformly distributed throughout a diurnal cycle, we could be confident that the apparent habitat relationships were unbiased. We were not concerned about the seasonal continuity of tag locations since our analysis was based only upon the co-occurrence of whale location and habitat (i.e., we needed a location for an event to be included in the habitat analysis). When a tag stopped transmitting, our frequencies were simply reduced in number, yet the continuity assumption required for our $\mathrm{K}-\mathrm{S}$ test was met (even though our statistical precision was reduced with the smaller sample size). Behavioural bias was a much more complicated issue since it was inherent to the relationships under investigation. For the purpose of this paper, we assumed that the behavioural bias was small and constant across region, season, and gender. We do, however, refer to behavioural bias in our interpretation of results.

The whale-habitat relationship indicates how the animals move in relation to habitat features, but it does not reveal the geographic distribution of the animals. To address geographic distribution, we computed the frequency of locations within a $5 \mathrm{~km}^{2}$ sampling interval within the seasonal periods of $\mathrm{S} 1$ (summer: up to and including September 18) and S2 (fall: after September 18) for both 
the east and west subregions. The resulting GIS maps show the numerical frequency of locations on a $5 \mathrm{~km}^{2}$ sampling grid within each subregion. The frequency data were spatially heterogeneous because animals may dwell for an extended period within a $5 \mathrm{~km}^{2}$ region, then travel rapidly to another site. This behaviour would result in large dwelltime values in one square, perhaps zero or very low values in the adjacent squares, until eventually the animal increased its dwell-time within another area. To establish a trend in these spatial relationships, we convolved a circular Gaussian filter of radial dimension 10 with the original dwell-time data. This technique creates a low-magnitude trend surface showing the general dwell-time behaviour of the animals within each region. We saved the trend surface as a grey-scale image and created a contour plot of the dwell-time frequencies derived from the original frequency data. Both of these data sets were geometrically corrected onto a shoreline mask of the study sites, thereby showing the geographic dwell-time behaviour of the whales for each region and season.

The contour plots and grey-scale trend surfaces in Figure 3 overlap with the land in many locations because the radial Gaussian kernel increases the spatial dimension of the trend surface in both $\mathrm{X}$ and $\mathrm{Y}$. Thus when animals occur in narrow channels, the technique smoothes this relationship away from the centre point of high dwelltime, often overlapping with adjacent land masses.

\section{RESULTS AND DISCUSSION}

\section{Assumption Testing}

Our analysis requires that the telemetry observations be statistically continuous to meet the assumptions of the $\mathrm{K}-\mathrm{S}$ test. To examine this requirement, we plotted the frequency of locations for all whales. This analysis revealed a small yet distinct diurnal bias in the telemetry locations (Fig. 2). This periodicity is a direct result of the orbital path of the Argos satellite. There are sinusoidal periods during the orbital cycle when coverage of the telemetry area changes. We also examined the frequency histograms for whales by region and season and found the same periodic pattern (histograms not shown). This confirms that there is a diurnal bias in the telemetry position locations but that the distribution of locations is still continuous (no systematic breaks), thus meeting the K-S test assumption. As with any systematic bias, so long as the whale-habitat relationship does not follow the periodicity bias exactly, we can consider our statistical relationship to be an unbiased reflection of the true whale-habitat relationship.

To provide a spatial context for our statistical analysis, we produced the frequency of location information (dwelltime) relative to the geography of the west and east subregions. Results show that the animals in the east were located most often (highest dwell-times) in Peel Sound during the summer season. A second mode of high dwell-times

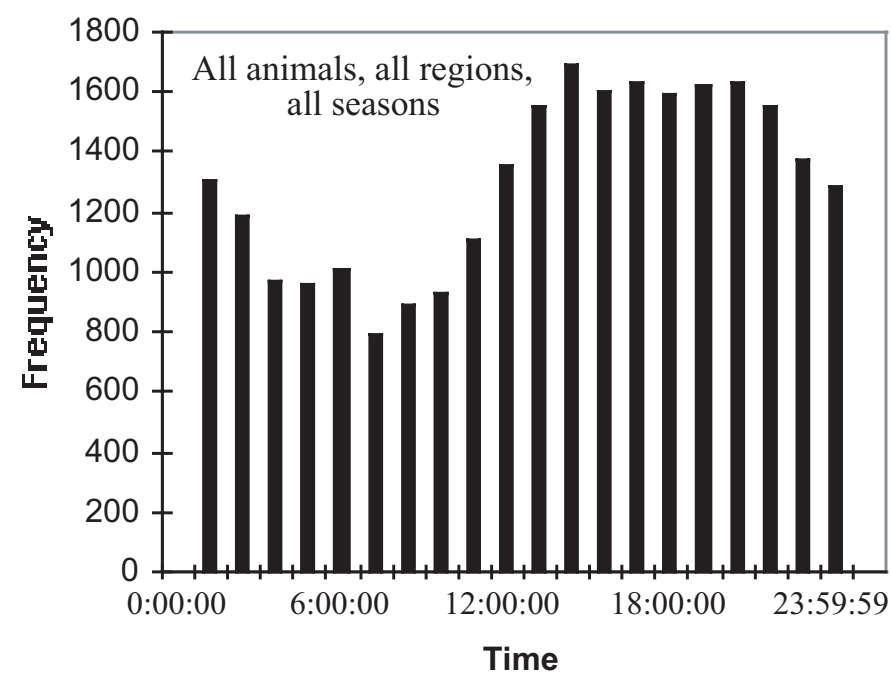

FIG. 2. The diurnal cycle of beluga locations (frequency of tag locations as a function of time of day) during the period when tags were transmitting.

was associated with the east coast of Devon Island, and a distinct travel corridor through Barrow Strait and Lancaster Sound connected these high dwell-time locations. In the fall, the distribution of dwell-times changed considerably. The highest dwell-times occurred principally along the east coast of Devon Island, with a second mode inside Jones Sound. The animals also occurred within the southern limits of the North Water polynya and along the west coast of Greenland, although the frequencies of dwelltimes suggest that the animals were travelling rapidly through these areas (low dwell-time values in Fig. 3).

In the west, the highest dwell-times were in the Mackenzie Estuary and within a deep trench located within M'Clure Strait and Viscount Melville Sound. An intermediate dwell-time mode was located offshore along the edge of the Beaufort Sea pack ice, and smaller modes were evident within Amundsen Gulf and in a travel corridor between the Mackenzie Estuary and M'Clure Strait. The dwell-time data suggest that the animals were much more diffusely distributed in the fall. Modes of high dwell-time occurred again within the Mackenzie Estuary and Amundsen Gulf and north along the Yukon Coast (near Cape Herschel). There were also several intermediate modes located offshore near the margins of the pack ice. The low dwell-time corridors suggest that animals are using different travel corridors to reach locations of high dwell-time (Fig. 3). Further descriptions of the movements that led to these distributions of locations are given by Richard et al. (2001a, b).

\section{Habitat Selection}

To address the first of our three research questions, we considered all 19969 locations from both the east and west subregions. Frequency distributions of whale locations versus bathymetry and a random sample of locations relative to the same bathymetry produce two very different 


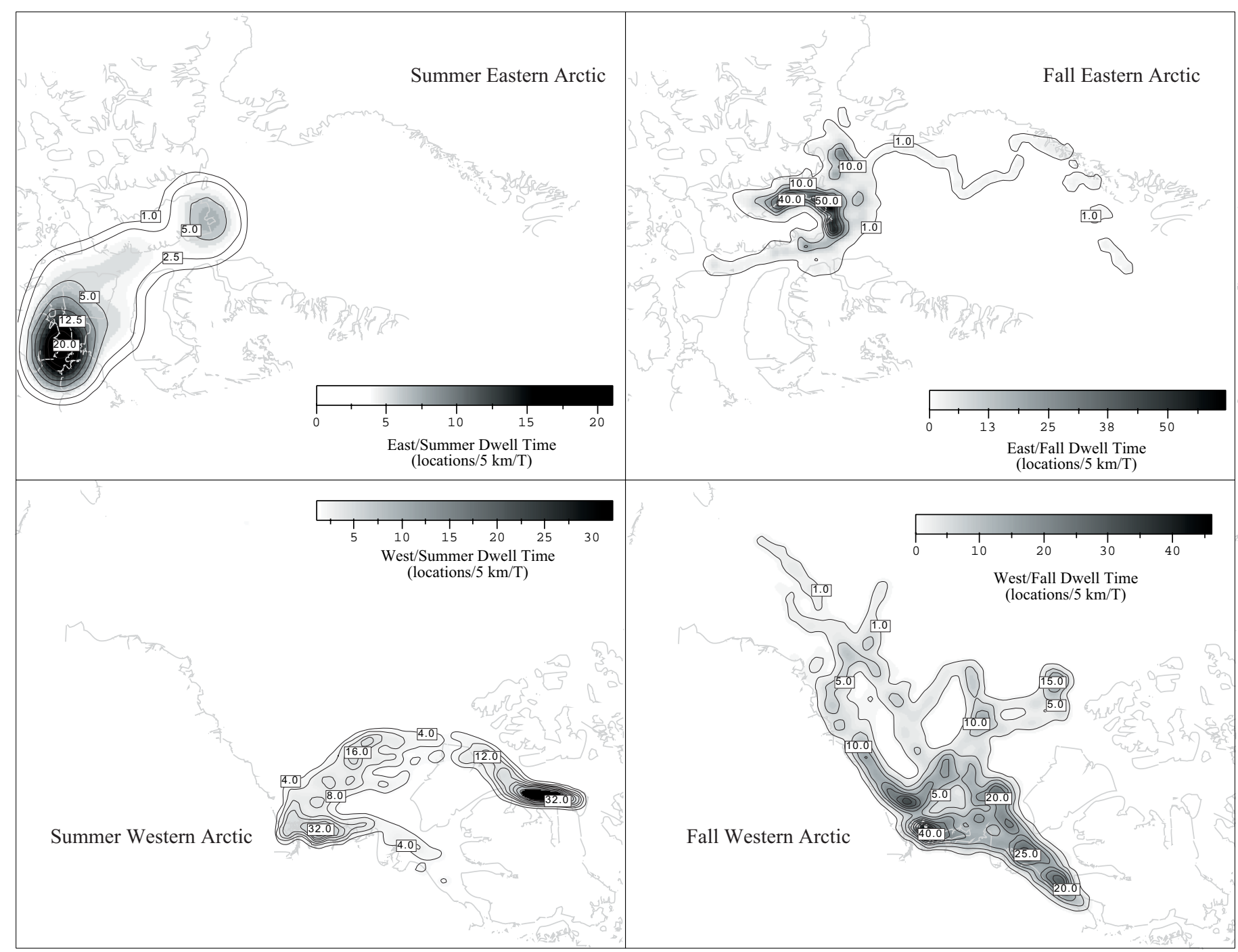

FIG. 3. Frequency of location (dwell-time) information, expressed as number of locations per $5 \mathrm{~km}$ per unit time, for belugas tagged in the eastern and western North American Arctic in summer and fall, 1993-96.

histograms (Fig. 4). The histograms suggest that the animals are associated with depth in a bimodal type of distribution, with large modes in shallow water and in waters approximately $500 \mathrm{~m}$ deep (Fig. 4). The cumulative frequency distribution (grey curve) suggests that there is a strong difference between the two distributions, and results from the K-S test strongly reject the null hypothesis that they arise from the same parent distribution $(p=0.000)$. We conclude that the animals are distributed relative to bathymetry in a much different way than would be expected by chance. Although no causal relationship can be inferred from this result, it would appear that belugas prefer particular bathymetry classes. Belugas have long been known to congregate in estuaries in the summer (Sergeant and Brodie, 1975), apparently to enhance their skin molt (St. Aubin et al., 1990). In the Beaufort Sea and Baffin Bay regions, they also seek deep areas (300-600 m) in the summer, particularly in Viscount Melville Sound, Amundsen Gulf, and Peel Sound (Smith and Martin, 1994; Richard et al., 2001a, b). Other deep areas, such as Jones
Sound and Lady Ann Strait in N.W. Baffin Bay (400$800 \mathrm{~m}$ ), are also visited in the fall (Richard et al., 1998). Dives in those areas frequently reach the seabed, where the whales are presumed to feed (Martin and Smith, 1990; Heide-Jørgensen et al., 1998; Richard et al., 2001a, b).

A behavioural bias may have affected our results. If an animal spends more time away from the surface in deep water than in shallow water, there would be a tendency for the frequencies to decrease as a function of depth. We speculate that this bias (if it exists) is very small because the frequency histogram is decidedly bimodal. If a strong bias existed, we would expect a more uniform reduction in frequencies with depth, not a bimodal distribution $(500 \mathrm{~m}$ and shallow water).

We also found a significant $(p=0.000)$ difference between the real and the random locations relative to sea ice (Fig. 5). Direct examination of the empirical probabilities of the real versus the random distributions suggests that belugas occur more often than would be expected by chance in the 0/10 ice class and less often in the 10/10 


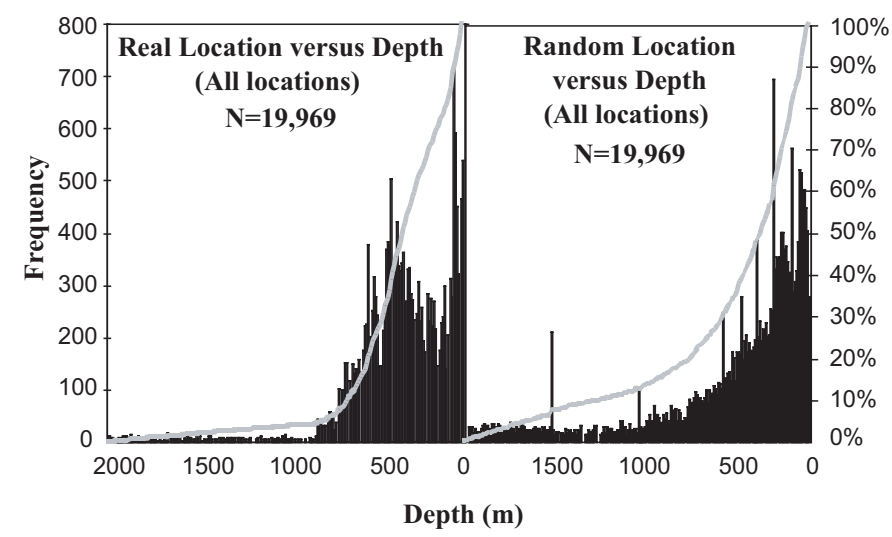

FIG. 4. Real and random locations in relation to bathymetry for the entire telemetry data set (19969 locations). The black histogram shows the frequencies at each depth, and the grey line represents the cumulative frequency distribution.

class. There is generally more agreement between the observed and random locations for the intermediate ice concentrations (1/10 to 9/10). It is interesting that, even though the frequency of whales located within the 10/10 class is lower than expected, the number of locations within this heavy-ice concentration class is still large. In fact, the empirical probabilities are larger in the 10/10 class than in the $0 / 10$ class. It is noteworthy that these belugas were using 10/10 ice concentration areas to reach the central Arctic Archipelago even though heavy ice has been hypothesized to act as a barrier to beluga movement across the central North American Arctic (Sergeant and Brodie, 1975).

A behavioural bias may also occur within this analysis, particularly in the heavier ice classes. This is because there would tend to be fewer successful telemetry positions in the higher ice concentrations. Given the large frequency in the $10 / 10$ class (relative to the $0 / 10$ class), we consider this bias to be minimal.

\section{Gender and Region-Based Habitat Selection}

Our second research question concerns differences in these whale-habitat relationships according to gender (Fig. 6). As expected, the random female and random male distributions are statistically indistinguishable (K-S, $p$ value $=0.895$ ). When we compare the real and random distributions, we find for both females and males that the real and random distributions are very different (K-S, $p=0.000$ in each case). Furthermore the real female and male distributions are significantly different $(\mathrm{K}-\mathrm{S}$, $p=0.038)$ from each other. We speculate that much of this difference may be due to the behaviour of females accompanied by calves. Mother-calf pairs are believed to spend longer periods in shallow water than other age or gender classes. The histograms suggest that both males and females use most depths of $800 \mathrm{~m}$ or less, and there is an indication of a bimodal association with deep $(\sim 300-500 \mathrm{~m})$ and shallow modes (Fig. 6). As stated earlier, this bimodality is a result of the occurrence of belugas in estuarine

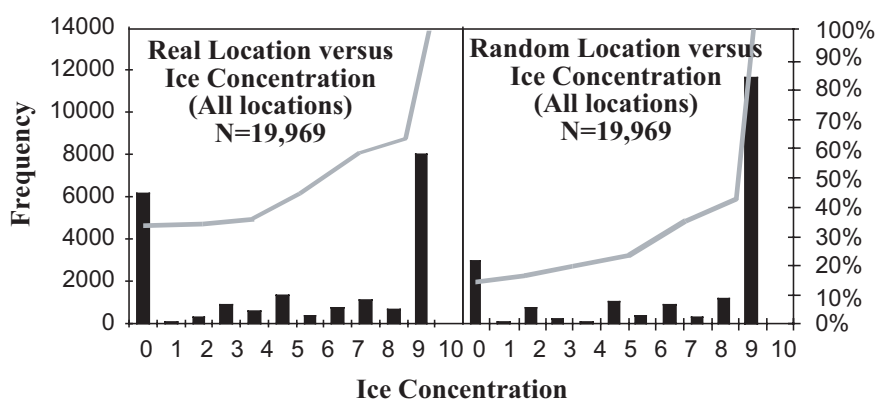

FIG. 5. Real and random locations in relation to ice concentration (in tenths) for the entire telemetry data set (19969 locations). The black histogram shows the frequencies at each ice concentration, and the grey line shows the cumulative frequency distribution.

habitats and in deep channels in the archipelago and the deeper shelf waters of the Beaufort Sea (Fig. 3). The female distribution displays a wider mode around $350 \mathrm{~m}$, and there appears to be more separation of the modes for males than for females (i.e., there is a sharper decline in frequency between the two modes for males). We speculate that this difference is due to the segregation of males in the western Arctic in summer. In 1993 and 1995, most males tagged in the Mackenzie Estuary moved to Viscount Melville Sound, where they remained in a deep trench $500+m$ deep (Richard et al., 2001a). Females in the western Arctic frequently moved to a trough about $350+\mathrm{m}$ deep in Amundsen Gulf. Males also spent some time in $1500 \mathrm{~m}$ depths off the continental shelf in the Arctic basin (Fig. 6).

Cumulative frequency distributions of male and female locations relative to ice concentration are significantly different than what would be expected from an equivalent random distribution of locations relative to ice concentration ( $p$ values in both cases are 0.000 ). Females spent more time in light ice (0/10) and less in heavy ice (10/10) than would be expected by chance. There is a tendency for females to be associated with the intermediate ice classes more often than would be expected by chance (larger individual frequencies in the real versus the random histograms in Fig. 7). We speculate that the higher-thanexpected frequencies in the intermediate classes mean that females are at times seeking that type of ice cover. The reason(s) could be related to the presence of under-ice prey or to the shelter from wind and waves offered by ice. We speculate that the lower-than-expected use of areas with heavy ice is related to the presence of calves, which makes females reluctant to risk ice entrapment. Also, the limited diving abilities of calves might mean that they are unable to negotiate long distances between breathing holes.

The data indicate that females and males associate with ice concentration differently. The male and female histograms in Figure 7 show that the largest contribution to this statistical difference arises from the fact that males are more strongly associated with the $0 / 10$ ice class.

The eastern and western animal locations are also distributed very differently from their random location 


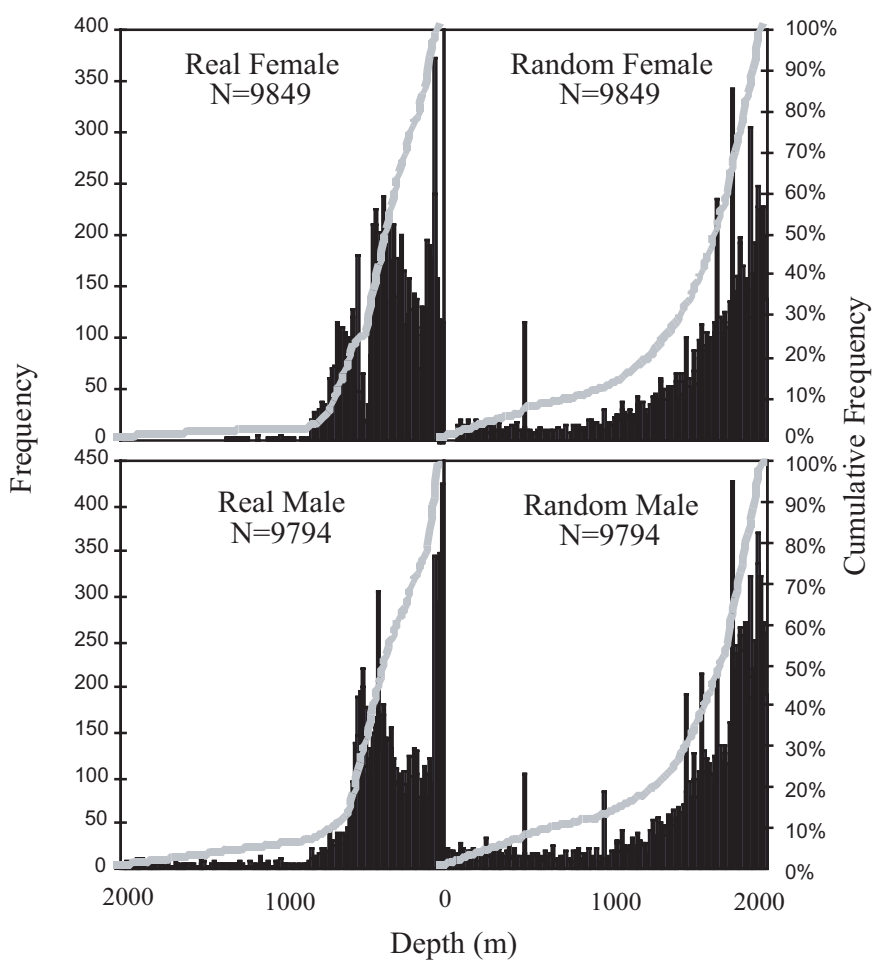

FIG. 6. Real and random locations in relation to bathymetry for male and female belugas from all regions and seasons. The grey line shows the cumulative frequency distribution.

equivalents (both K-S, $p=0.000$ ) in relation to bathymetry (Fig. 8). Also, the animals in the east associate with bathymetry very differently than the animals in the west do $(p=0.000)$, even though the distributions of the random locations relative to depth (east versus west) are not significantly different $(p=0.103)$. This means that the distribution of the habitat (in this case, depth) is not statistically distinguishable, but the whales in the two regions select different depth strata. Belugas from the Mackenzie Estuary use deep offshore areas on their way to M'Clure Strait rather than using the shallower waters near Banks Island (cf. Figs. 3 and 8).

Consideration of the ice habitat variable indicates a situation similar to that of bathymetry (Fig. 9). The distributions of real locations in both the east and the west are significantly different from their random counterparts (both $\mathrm{K}-\mathrm{S}, p=0.000$ ). The difference between the east random and the west random is also statistically significant $(p=0.000)$; thus, the distribution of ice concentration differs between the two regions. Eastern and western whales clearly associate with sea ice in very different ways. For example, a higher proportion of whale locations in the west is associated with the $0 / 10$ ice class, and a lower proportion is associated with the $10 / 10$ class (Fig. 9). We speculate that this distribution is a function of the fact that there is proportionately less habitat with $0 / 10$ ice coverage available in the east than in the west. Moreover, the extent of ice-free areas (including estuarine habitats) is smaller in the east.

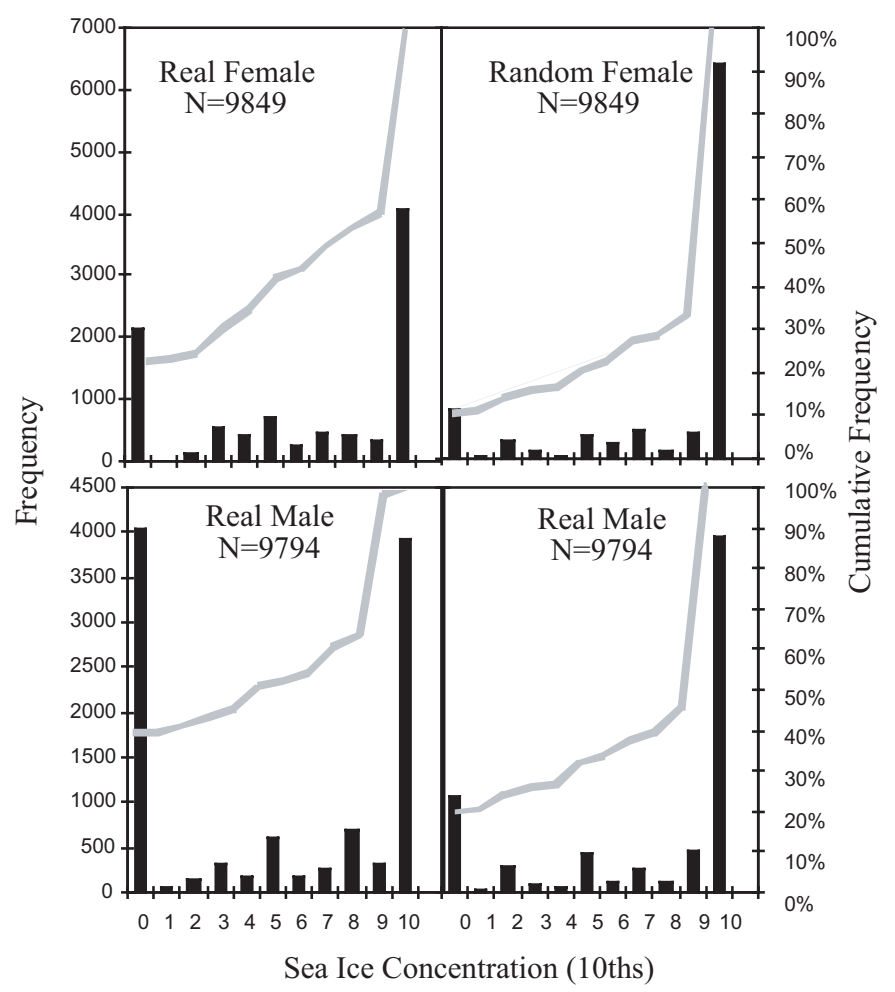

FIG. 7. Real and random locations in relation to ice concentration (in tenths) for male and female belugas from all regions and seasons. The grey line shows the cumulative frequency distribution.

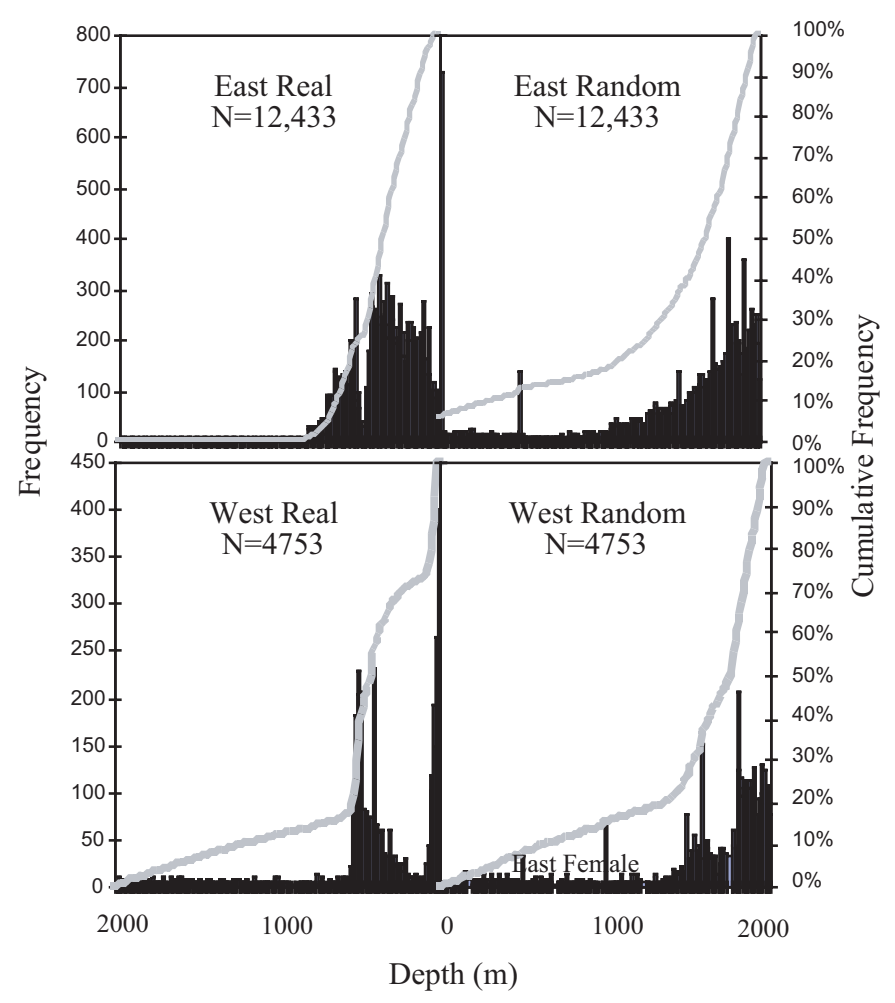

FIG. 8. Real and random locations in relation to bathymetry for eastern and western portions of the study area. The grey line shows the cumulative frequency distribution. 


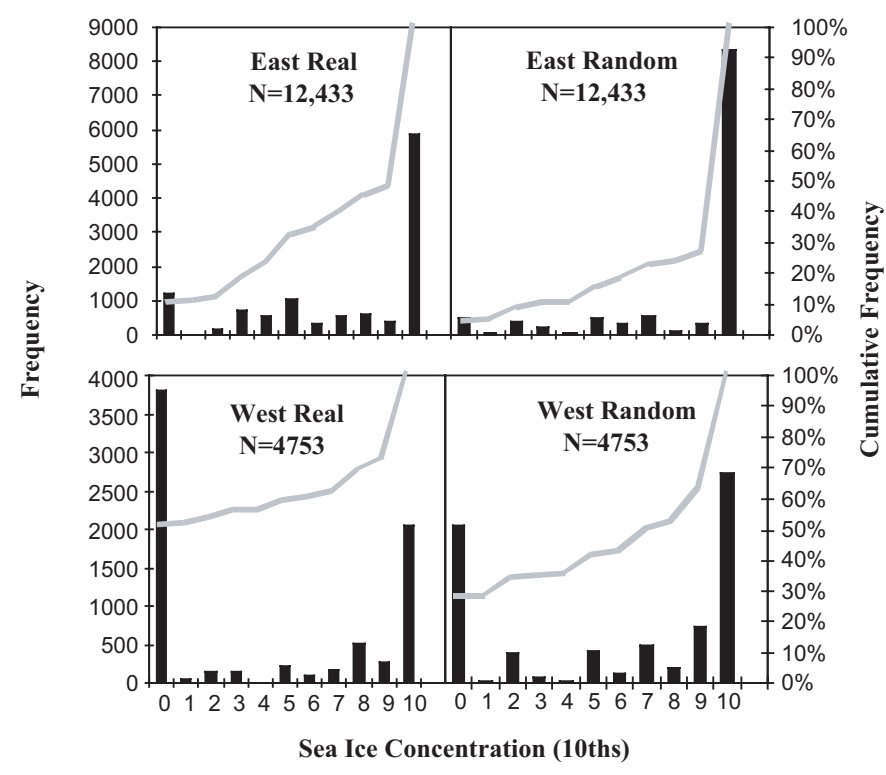

FIG. 9. Real and random locations in relation to sea ice concentration (in tenths) for eastern and western portions of the study area. The grey line shows the cumulative frequency distribution.

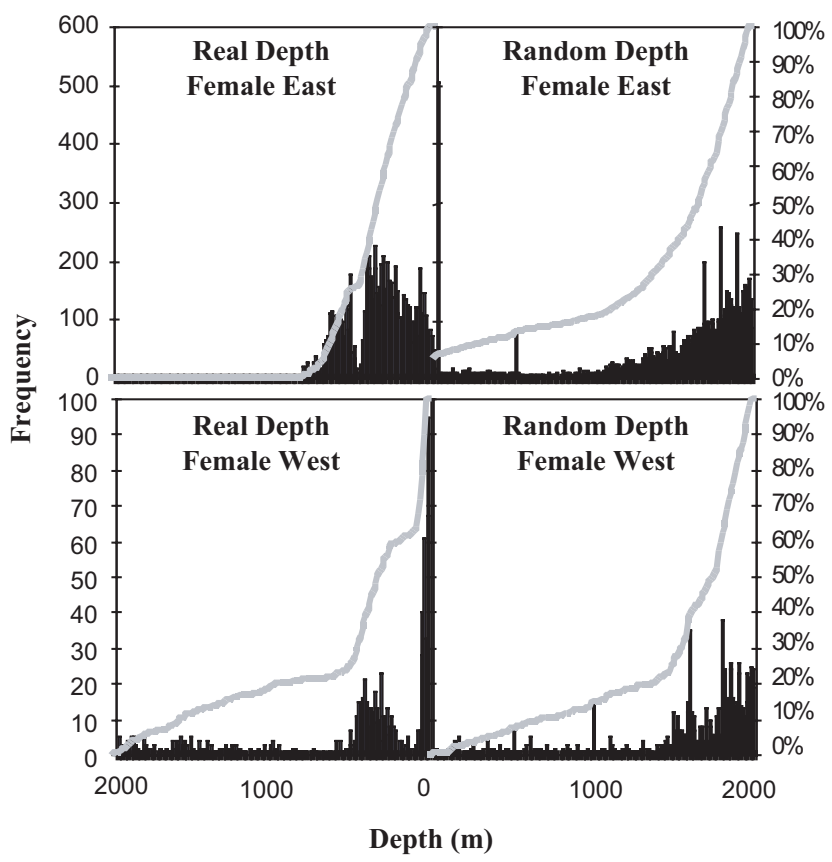

FIG. 10. Real and random locations in relation to bathymetry for female belugas in the western and eastern portions of the study area. The grey line shows the cumulative frequency distribution.

In our next series of analyses, we examined how females associated with bathymetry in the two regions (Fig. 10). Females in the west strongly selected the shallow water class, whereas the eastern females selected a much deeper (mean of about $400 \mathrm{~m}$ ) and narrower range of depths. The strong bimodal distribution in the west suggests that the behaviour of whales there differs from that of whales in the east. The short peak at about $350 \mathrm{~m}$ and the long tail to $2000 \mathrm{~m}$ are due to the fact that western females

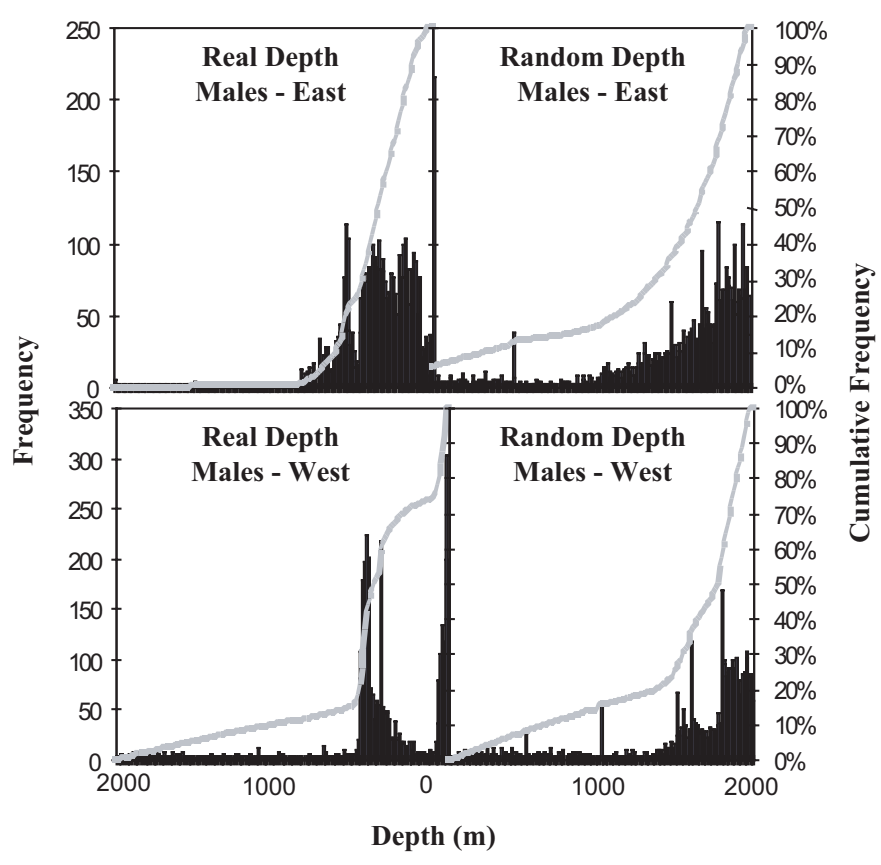

FIG. 11. Real and random locations in relation to bathymetry for male belugas in the western and eastern portions of the study area. The grey line shows the cumulative frequency distribution.

moved back and forth between the Mackenzie Estuary, the shelf break, and Amundsen Gulf, thereby covering many depth strata. Females in the east spent most of the summer in the deep trench $(400+\mathrm{m})$ of Franklin Strait (southern Peel Sound), where they ranged in waters $5-450 \mathrm{~m}$ deep. Eastern females then moved in early fall to the nearshore but deeper waters off southern and eastern Devon Island (depths to $500 \mathrm{~m}$ ), but we have few positions from this area.

The pattern for males is similar to that for females, and some characteristics of the bathymetric relationship are more pronounced (Fig. 11). For example, the bimodal distribution in the west is much stronger for males. The sharp peak at about $500 \mathrm{~m}$ for western males is due to the animals' spending extended periods in the deep trench of Viscount Melville Sound. Eastern males moved across a greater variety of depths than western males. There was still a strong selection for shallow water, but also a more pronounced mode at about $500 \mathrm{~m}$. The K-S statistics confirm that the female and male distributions are significantly different within each region ( $p=0.000$ in all cases).

Significant regional differences were also observed for each sex in its relationship to ice concentration (Figs. 12 and 13). In the east, there were significantly more whale locations in the $0 / 10$ ice class and fewer in the 10/10 class than would be expected by chance. In general, a larger proportion of locations was also associated with $2 / 10$ and 9/10 coverage (Figs. 12 and 13). Western females had more locations in the $0 / 10$ class and fewer locations in the $10 / 10$ class than expected by chance. There were also large differences in the classes between 2/10 and 9/10 (Fig. 12). 


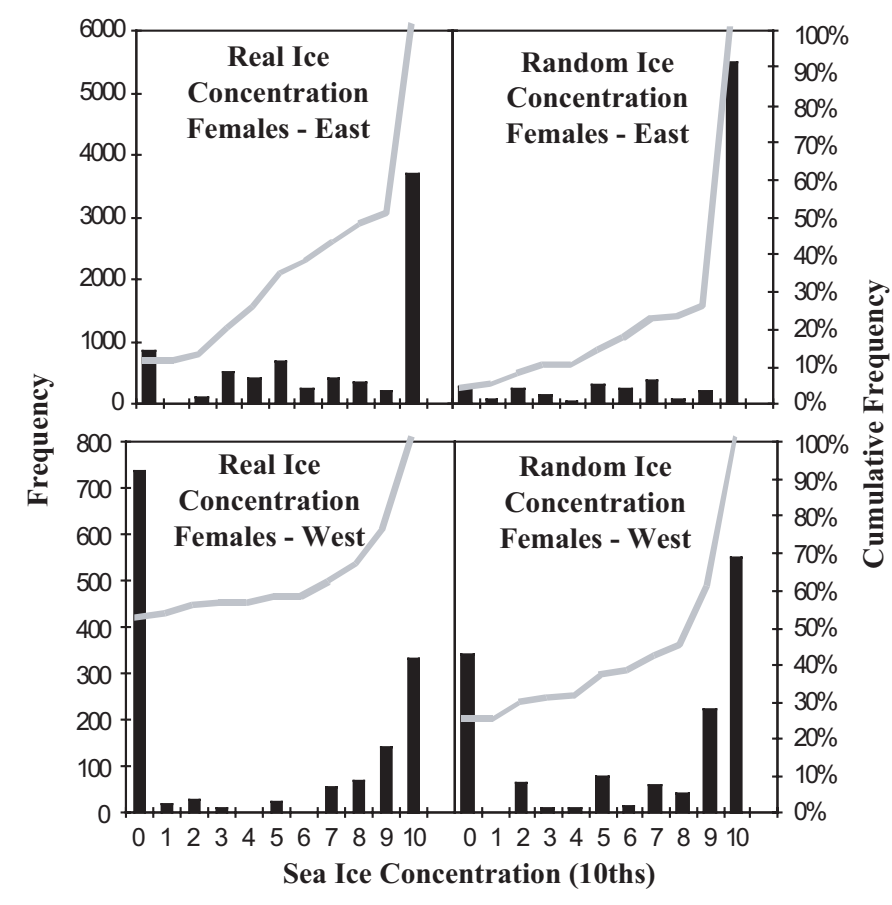

FIG. 12. Real and random locations in relation to ice concentration (in tenths) for female belugas in the western and eastern portions of the study area. The grey line shows the cumulative frequency distribution.

\section{Gender and Season-Based Habitat Selection}

When season is considered, the number of combinations increases. In this analysis, we consider only two seasonal periods: summer (S1: up to and including Sept 18) and fall (S2: after Sept 18). To present combinations of regions (E or W), sexes (M or F), and the observed ("real") versus random pairing, we required 16 histograms for bathymetry (Fig. 14) and another 16 for sea ice concentration (Fig. 15).

Results for the bathymetry relationships (Fig. 14) show that in the summer period, females in both the east (E, S1, F, Real) and the west (W, S1, F, Real) distributions were significantly different from the random location distributions. Also, females in the east associated with bathymetry very differently in the fall (E, S2, F, Real). In general, females preferred shallower water in the summer and deeper water in the fall. Unfortunately, there were not enough female locations in the west for the fall (W, S2, F, Real) to provide a meaningful comparison of the cumulative frequency histograms.

Male locations in the east were significantly different from the random distributions for both summer and fall (Fig. 14). During the summer, males in the east tended to be associated with the shallow-water classes, with a large, diffuse mode between 0 and $500 \mathrm{~m}$. In the fall (E, S2, M, Real), there was a deeper-water association, with modes at 100 and $500 \mathrm{~m}$ (Fig. 14). In the west, there were two distinct modes at about $500 \mathrm{~m}$ and $20 \mathrm{~m}$ (W, S1, M, Real). Again, there were not enough locations for meaningful conclusions regarding the fall period in the west (W, S2, M, Real).

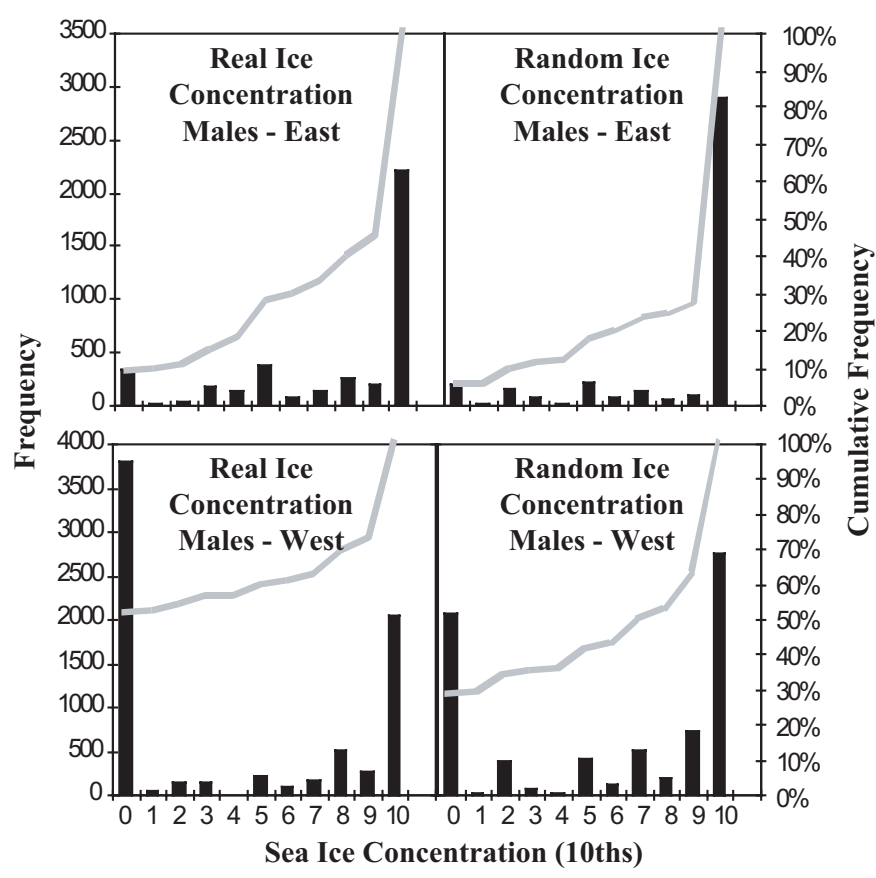

FIG. 13. Real and random locations in relation to ice concentration (in tenths) for male belugas in the western and eastern portions of the study area. The grey line shows the cumulative frequency distribution.

Results for sea ice concentration showed several differences across the various combinations of gender, region, and season (Fig. 15). More female locations were associated with the low (0/10) and high (10/10) ice concentration classes than expected by chance. In the east, proportionally fewer locations were associated with the 0/10 ice concentration and slightly more with the intermediate ice concentration classes (E, S1, F, Real; Fig. 15). Male trends were similar. There were more male locations than expected in the $0 / 10$ class and fewer than expected in the $10 / 10$ class. In the west, there were also more locations associated with the $0 / 10$ class and fewer with the 10/10 class than expected by chance. In the fall (S2), fewer male locations were associated with the $0 / 10$ ice class (E, S2, M, Real) in the east and with the 10/10 class in the west (W, S2, M, Real) than in summer.

\section{CONCLUSIONS}

The objective of this paper was to examine the spatial and temporal relationships of belugas with two characteristics of their habitat: bathymetry and ice concentration. Considering two regions, two seasons, and both sexes, whale distribution in relation to depth showed a bimodal distribution, with the larger mode in shallow water and the smaller mode in water approximately $500 \mathrm{~m}$ deep. There was also a large difference between the real and the random distributions of whale locations in relation to ice conditions. Belugas occurred more often than expected by chance in the $0 / 10$ ice class and less often in the $10 / 10$ ice class. 
14.

4.375 by 5.1875

Reduce: $80 \%$

3.5 by 4.15 inches
15.

4.5 by 5.1875 inches

Reduce: $77.8 \%$

3.5 by 4.036 inches
FIG. 14. Relation of real and random whale locations to bathymetry, shown separately for males (M) and females (F) associated with east (E) and west (W) regions in summer (S1) and fall (S2) seasons. Paired random locations appropriate to each case are depicted as "Rand" in the figure.

Males and females associated differently with both depth and ice concentration. The difference in association with ice concentration is explained mainly by the fact that males associate with the $0 / 10$ ice class more consistently than females do.

Although belugas in the east and west have approximately the same spatial distribution of depths available to them, they associate with bathymetry differently. The reasons for this difference are currently unknown, but they probably indicate a real difference in either the ecological or behavioural characteristics of whales visiting these regions. Spatial distribution of sea ice was different within the two regions (because of atmospheric and oceanographic differences), and the animals associated with sea ice differently within each region.

With regard to seasonal differences, females associated with bathymetry very differently in the fall than in the summer. In general, females preferred shallower water in the summer and deeper water in the fall. Males in the east generally tended to be associated with the shallow-water classes more during the summer than in fall. Female locations in summer were associated more often with the $0 / 10$ ice class and less often with the 10/10 class than we would expect by chance. These trends were stronger in the west than in the east.

Our "dwell-time" analysis showed that the animals in the eastern Arctic occurred most often (highest dwell-times)
FIG. 15. Relation of real and random whale locations to ice concentration (in tenths), shown separately for males (M) and females (F) associated with east (E) and west (W) regions in summer (S1) and fall (S2) seasons. Paired random locations appropriate to each case are depicted as "Rand" in the figure.

in Peel Sound during the summer and moved to the east coast of Devon Island in the fall. In the western Arctic, the animals occurred most often in the Mackenzie Estuary and within a deep trench in M'Clure Strait and Viscount Melville Sound during the summer. In the fall, the whales occurred in the Mackenzie Estuary and Amundsen Gulf and north along the Yukon Coast. The dwell-time analysis showed that the spatial pattern of animal locations varied significantly between the summer and fall in both the east and the west.

The analyses presented here represent an initial attempt to interpret a combined telemetry and habitat GIS database. The basic methodological premise of our work so far has been that of correspondence analysis (whale location and habitat variables coincide in space and time). The next logical step is to examine spatial association at scales larger than correspondence (i.e., distance association). It would also be possible to look more deeply into animal behaviour by using dwell-time as a proxy. For example, areas with low dwell-times could be defined as travel corridors when whale headings are estimated by examining movement direction relative to time. High dwell-times can be related to behaviour by examining depth relationships and diving behaviour within these regions. The GIS also provides a logical framework for integration of other variables, such as traditional ecological knowledge, aerial survey abundance estimates, and more complex habitat variables such as ice type (e.g., first-year, 
multiyear, new ice), water temperature, and marine productivity (chlorophyll).

Our results show that animals select particular classes of sea ice concentration and water depth, presumably because both relate to factors such as prey distribution, predation, weather, molting, and the rearing of young. We see these results as a prerequisite to understanding why belugas select particular habitats. Once their reasons are better understood, we may be able to predict how belugas will respond to changes in the biophysical conditions of the Arctic marine environment.

\section{ACKNOWLEDGEMENTS}

This work was supported by a Natural Sciences and Engineering Research Council (NSERC) Grant to D. Barber; a service contract from the Department of Fisheries and Oceans and the Fisheries Joint Management Committee; and analysis support from the Centre for Earth Observation Science, Department of Geography, University of Manitoba. We are grateful to A.R. Martin and the Sea Mammal Research Unit and M.P. Heide-Jørgensen of the Greenland Institute of Natural Resources for their support in obtaining the location data and to Brad Sparling for database development. Thanks also for a pre-review from R. Reeves and D. St Aubin and blind reviews from two Arctic reviewers. We thank I. Harouche and D. Fast (University of Manitoba) for drafting assistance. Many others acknowledged in Richard et al. (2001a, b) made this work possible through funding and assistance in field work and location data processing.

\section{REFERENCES}

FINLEY, K.J., MILLER, G.W., ALLARD, M., DAVIS, R.A., and EVANS, C.R. 1982. The belugas (Delphinapterus leucas) of northern Quebec: Distribution, abundance, stock identity, catch history and management. Canadian Technical Report of Fisheries and Aquatic Sciences 1123. 57 p.

HEIDE-JØRGENSEN, M.P., RICHARD, P.R., and ROSINGASVID, A. 1998. Dive patterns of belugas (Delphinapterus leucas) in waters near eastern Devon Island. Arctic 51:17-26.

IPCC (INTERGOVERNMENTAL PANEL ON CLIMATE CHANGE). 1996. Climate change: The IPCC assessment. Edited by J.T. Houghton, G.J. Jenkens, and J.J. Ephraums. Cambridge: Cambridge University Press.

JOHANNESSEN, O.M., SHALINA, E.V., and MILES, M.W. 1999. Satellite evidence for an Arctic sea ice cover in transformation. Science 286:1937-1940.
MacNAB, R., and MONAHAN, D. 1997. Digital bathymetric observations from the Arctic, extracted from Canadian and public-domain archives. Arctic Bathymetry Workshop, VNII Okeangeolia, St. Petersburg, Russia, 18-19 September 1997.

MARTIN, A.R., and SMITH, T.G. 1990. Deep diving in wild, freeranging beluga whales, Delphinapterus leucas. Canadian Journal of Fisheries and Aquatic Sciences 49:462-466.

McLAREN, P.L., and DAVIS, R.A. 1982. Winter distribution of Arctic marine mammals in ice-covered waters of eastern North America. Unpubl. report to the Offshore Labrador Biological Studies (OLABS) Program by LGL Environmental Research Associates Ltd. Toronto. Available at the Department of Fisheries and Oceans, Freshwater Institute, 501 University Crescent, Winnipeg, Manitoba R3T 2N6. 151 p.

MOORE, S.E., and DeMASTER D.P. 1998. Cetacean habitats in the Alaskan Arctic. Journal of Northwest Atlantic Fisheries Science 22:55-69.

PARKINSON, C., CAVALIERI, D., GLOERSEN, P., ZWALLY, H., and COMISO, J. 1999. Arctic sea ice extents, areas, and trends, 1978-1996. Journal of Geophysical Research (Oceans). C9:20837-20856.

RICHARD, P.R., HEIDE-JØRGENSEN, M.P., and ST. AUBIN, D. 1998. Fall movements of belugas (Delphinapterus leucas) with satellite-linked transmitters in Lancaster Sound, Jones Sound, and northern Baffin Bay. Arctic 51(1):5-16.

RICHARD, P.R., MARTIN, A.R., and ORR, J.R. 2001a. Summer and autumn movements of belugas of the eastern Beaufort Sea stock. Arctic 54(3):223-236.

RICHARD, P.R., HEIDE-JØRGENSEN, M.P., ORR, J.R., DIETZ, R., and SMITH, T.G. 2001b. Summer and autumn movements and habitat use by belugas in the Canadian High Arctic and adjacent areas. Arctic 54(3):207-222.

ROTHROCK, D.A, YU, Y., and MAYKUT, G.A. 1999. Thinning of the Arctic sea ice cover. Geophysical Research Letters 26:3469-3472.

SERGEANT, D.E., and BRODIE, P.F. 1975. Identity, abundance, and present status of populations of white whales, (Delphinapterus leucas) in North America. Journal of the Fisheries Research Board of Canada 32:1047-1054.

SMITH, T.G., and MARTIN, A.R. 1994. Distribution and movements of belugas, Delphinapterus leucas, in the Canadian High Arctic. Canadian Journal of Fisheries and Aquatic Science 51:1653-1663.

SOKAL, R.R., and ROHLF, F.J. 1981. Biometry. New York: W.H. Freeman and Company.

ST. AUBIN, D.J., SMITH, T.G., and GERACI, J.R. 1990. Seasonal epidermal molt in beluga whales, Delphinapterus leucas. Canadian Journal of Zoology 68:359-367. 